\title{
Effect of annealing temperature on microstructure and mechanical properties of a high Al-low Si TRIP steel
}

\author{
Yang Zhao ${ }^{1}$, Liqing Chen ${ }^{2, a}$, Qiangjun $\mathrm{Yan}^{3}$, and Changsheng $\mathrm{Li}^{2}$ \\ ${ }^{1}$ School of Materials and Metallurgy, Northeastern University, Shenyang 110819, PR China \\ ${ }^{2}$ State Key Laboratory of Rolling and Automation, Northeastern University, Shenyang 110819, \\ PR China \\ ${ }^{3}$ New Product Development and Application Center, Nanjing Iron and Steel Co., Ltd., Nanjing \\ 210035, PR China
}

\begin{abstract}
By using optical microscope (OM), scanning electron microscope (SEM), transmission electron microscope (TEM), X-ray diffraction (XRD), electron back scattered diffraction (EBSD) and tensile test, the effect of annealing temperature on microstructure and mechanical properties of a high Al-low Si TRIP steel was investigated. The results show that TRIP effect can be obtained when annealing temperature is above $A_{c 3}$ due to the existence of $\delta$-ferrite in this high Al-low Si TRIP steel. That is to say, the microstructure consisting of ferrite, bainite and retained austenite can be obtained when annealing temperature is above $A_{c 3}$. Furthermore, the tensile strength and the product of strength and elongation decrease with increasing annealing temperature when annealing temperature is above $A_{c 3}$.
\end{abstract}

\section{Introduction}

Reduction in the weight of automobile bodies has been continuously needed in order to improve the fuel efficiency and to reduce the amount of emission gas for better environmental preservation [1]. This led to huge demands for high strength steels with excellent formability. There have been a lot of interests in transformation induced plasticity (TRIP) steels due to their excellent combination of high strength, enhanced formability and good crashworthiness, and they have potential for application in crash-relevant parts in automobiles [1,2]. Essentially, enhanced formability and energy absorption behavior can be attributed to the TRIP effect, which is the transformation of the retained austenite phase in the microstructure to martensite upon straining [3].

The conventional TRIP steels usually have high silicon content (about 1.5 wt.\%) to prevent the precipitation of cementite and to enhance the stability of retained austenite. However, the high silicon content will result in bare spot defects during galvanizing process [4]. To avoid this problem, silicon can be partially replaced by aluminum in some TRIP steels in order to improve the reactive wetting

\footnotetext{
${ }^{\text {a }}$ Corresponding author: Iqchen@mail.neu.edu.cn
}

This is an Open Access article distributed under the terms of the Creative Commons Attribution License 4.0, which permits unrestricted use, distribution, and reproduction in any medium, provided the original work is properly cited. 


\section{MATEC Web of Conferences}

Table 1. Chemical composition of the experimental steel used in this study (in wt.\%).

\begin{tabular}{|c|c|c|c|c|c|c|c|}
\hline $\mathrm{C}$ & $\mathrm{Si}$ & $\mathrm{Mn}$ & $\mathrm{Al}$ & $\mathrm{Cr}$ & $\mathrm{P}$ & $\mathrm{S}$ & $\mathrm{Fe}$ \\
\hline 0.18 & 0.30 & 1.56 & 1.44 & 0.077 & 0.008 & 0.008 & Bal. \\
\hline
\end{tabular}

during hot-dip galvanizing [5]. Both silicon and aluminum are insoluble in cementite and greatly retard cementite formation [6]. So, aluminum can be used to replace silicon in TRIP steels. Since silicon seems most effective to prevent the formation of cementite during the austempering stage, it suggests that a partial replacement of silicon by aluminium is viable. The high aluminum content in TRIP steels results in a high carbon content in the retained austenite [5], which in turn enhances the mechanical stability of retained austenite.

An investigation performed by Chatterjee et al. shows that there exists $\delta$-ferrite in high Al-low $\mathrm{Si}$ TRIP steels [7]. That is to say, there exists ferrite in high Al-low Si TRIP steels at any temperature. For TRIP steels, the purpose of intercritical annealing treatment is to obtain ferrite and to enrich carbon content in austenite. Due to the existence of $\delta$-ferrite in high aluminum TRIP steel, ferrite can be obtained when annealing temperature is above $A_{c 3}$. Theoretically, typical microstructure of TRIP steels can be obtained in this case.

On the basis of a newly developed high Al-low Si TRIP steel, in this presentation the possibility of acquiring TRIP effect was further investigated for this steel by annealing at temperature above $A_{c 3}$.

\section{Experimental}

The chemical composition of the experimental steel used in this study is listed in Table 1 . This steel was melted in a vacuum induction furnace and cast to a $25 \mathrm{~kg}$ ingot. The ingot was then hot forged at $120{ }^{\circ} \mathrm{C}$ to a slab with a size of $50 \mathrm{~mm} \times 100 \mathrm{~mm} \times 120 \mathrm{~mm}$. The slab was subsequently hot rolled to a sheet of $4 \mathrm{~mm}$ thick at finish rolling temperature of $900{ }^{\circ} \mathrm{C}$. After pickling process, the steel sheet was finally cold rolled to $1 \mathrm{~mm}$ in thickness.

In order to determine $A_{c 1}$ and $A_{c 3}$ of the experimental steel, an automatic dilatometer (FormastorFII) was used to obtain the thermal expansion-temperature curve at a heating rate of $0.05^{\circ} \mathrm{C} / \mathrm{s}$. The specimen used for dilatometer was machined to a cylinder of $\varphi 3 \mathrm{~mm} \times 10 \mathrm{~mm}$ in size. The thermal expansion-temperature curve of the experimental steel is shown in Fig. 1. By using tangent method, $A_{c 1}$ is determined to be $790{ }^{\circ} \mathrm{C}$, while $A_{c 3}$ is calculated to be $895^{\circ} \mathrm{C}$. To verify the existence of $\delta$-ferrite in the experimental steel, the specimen was firstly heated to $1100{ }^{\circ} \mathrm{C}$ for $5 \mathrm{~min}$, and then water quenched to room temperature. After they were polished and etched by 4 vol.\% nital solution, the microstructure was observed in an optical microscope (LEICA DMIRM Q550IW). As shown in Fig. 2, the microstructure of the experimental steel consists of martensite $(\mathrm{M})$ and ferrite $(\mathrm{F})$. Since the austenitizing temperature is above $A_{c 3}$, it can be deduced that there exists $\delta$-ferrite $(\delta$-F).

Based on the measured results of $A_{c 1}$ and $A_{c 3}$, the annealing temperature was chosen to be 920,960 and $1000^{\circ} \mathrm{C}$, respectively. After the cold rolled steel sheets had been heated to the annealing temperature and held for $5 \mathrm{~min}$, the steel sheets were then quenched into a salt bath furnace and held at $450{ }^{\circ} \mathrm{C}$ for 5 min. Finally, the steel sheets were air cooled to room temperature.

The metallographic specimens were polished and etched with 4 vol.\% nital solution, and then observed in ZEISS ULTRA 55 scanning electron microscope (SEM). The electron back scattered diffraction (EBSD) measurements were also carried out in this SEM equipped with Oxford EBSD system. Transmission electron microscope (TEM) was employed to investigate the morphology and location of retained austenite. Thin foils for TEM observation were prepared by twin-jet electropolishing in $10 \mathrm{vol} . \%$ perchloric acid-alcohol solution $\left(-20^{\circ} \mathrm{C}\right)$ at a voltage of $20 \mathrm{~V}$. X-ray diffraction (XRD) specimen was first mechanically and then electrolytically polished to remove the residual stress introduced by grinding and surface layer polishing. The volume fraction of retained austenite was 


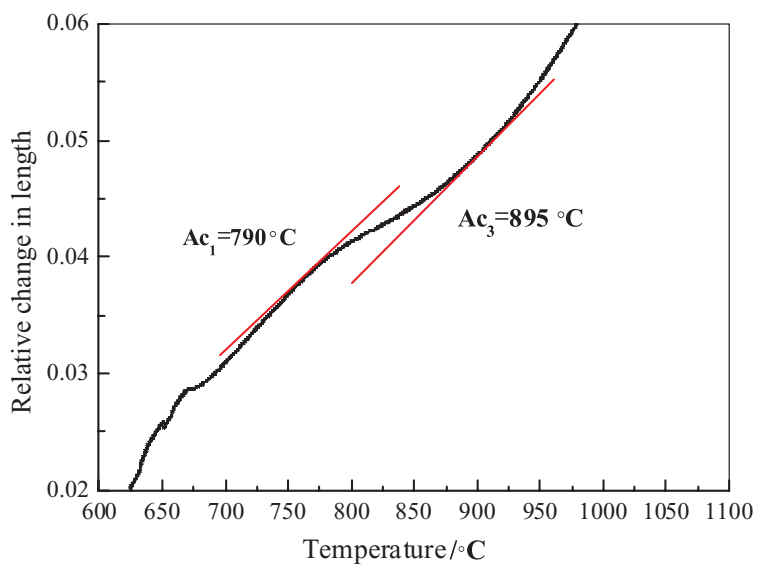

Figure 1. Thermal expansion-temperature curve of the experimental steel with heating rate of $0.05^{\circ} \mathrm{C} / \mathrm{s}$.

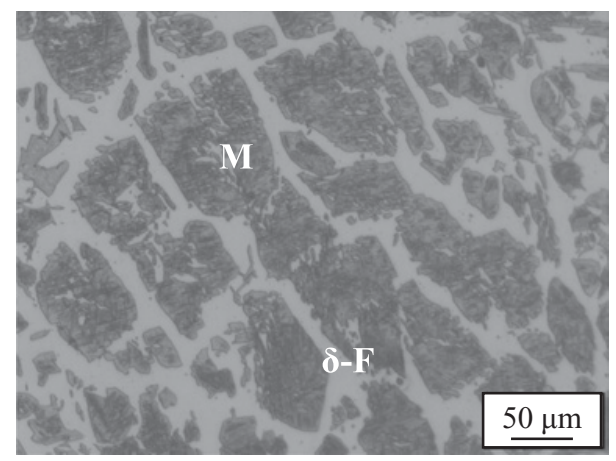

Figure 2. Optical micrograph showing the water-quenched microstructure of the experimental steel at $1100^{\circ} \mathrm{C}$.

measured and analyzed by XRD with $\mathrm{CuK} \alpha$ radiation. Calculation of the retained austenite can be found in Ref. [8], while the volume fraction of ferrite was calculated with Image-Pro Plus software. Assuming that the volume fractions of ferrite is $f_{F}$ and retained austenite is $f_{R A}$, respectively, then the volume fraction of bainite $\left(f_{B}\right)$ can be calculated from $f_{B}=1-f_{F}-f_{R A}$.

\section{Results and discussion}

\subsection{Microstructural characterization}

SEM microstructures of the experimental steel annealed at different temperatures are shown in Fig. 3. As can be seen in Fig. 3, the microstructures of high Al-low Si TRIP steel consist of ferrite (F), bainite (B) and retained austenite (RA). That to say, typical microstructure of TRIP steel can be obtained when annealing temperature is above $A_{c 3}$. There is no obvious difference in microstructures among the specimens treated at these three annealing temperatures.

As shown in Fig. 4, the retained austenite has two kinds of morphology, i.e. blocky and film-like retained austenite. Most of the blocky and film-like retained austenite is located at grain boundary, and the other can be found within ferrite or bainite. The morphology and location of retained austenite are consistent with the previous result in Ref. [8]. Furthermore, much blocky retained austenite can be obtained at lower annealing temperature. In contrast, much film-like retained austenite can be obtained at 

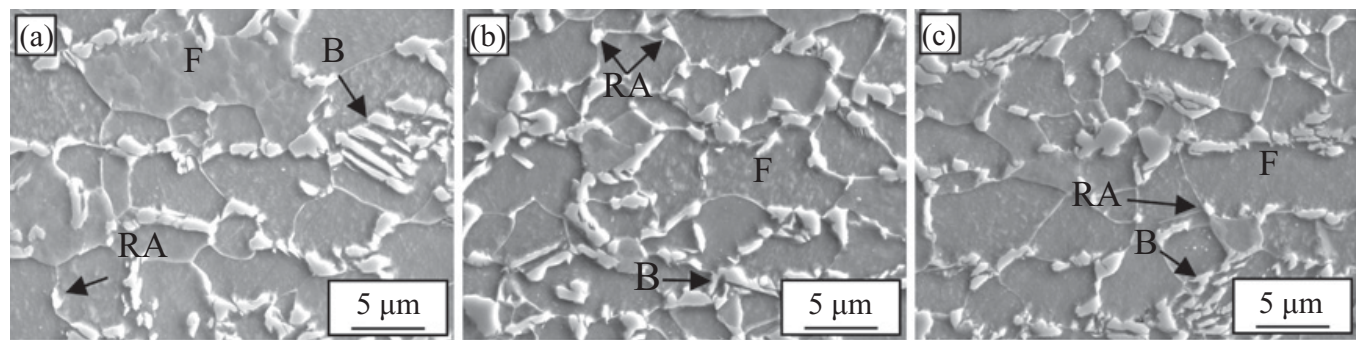

Figure 3. SEM microstructures of the steel annealed at different temperatures: (a) $920^{\circ} \mathrm{C}$, (b) $960{ }^{\circ} \mathrm{C}$, (c) $1000^{\circ} \mathrm{C}$.
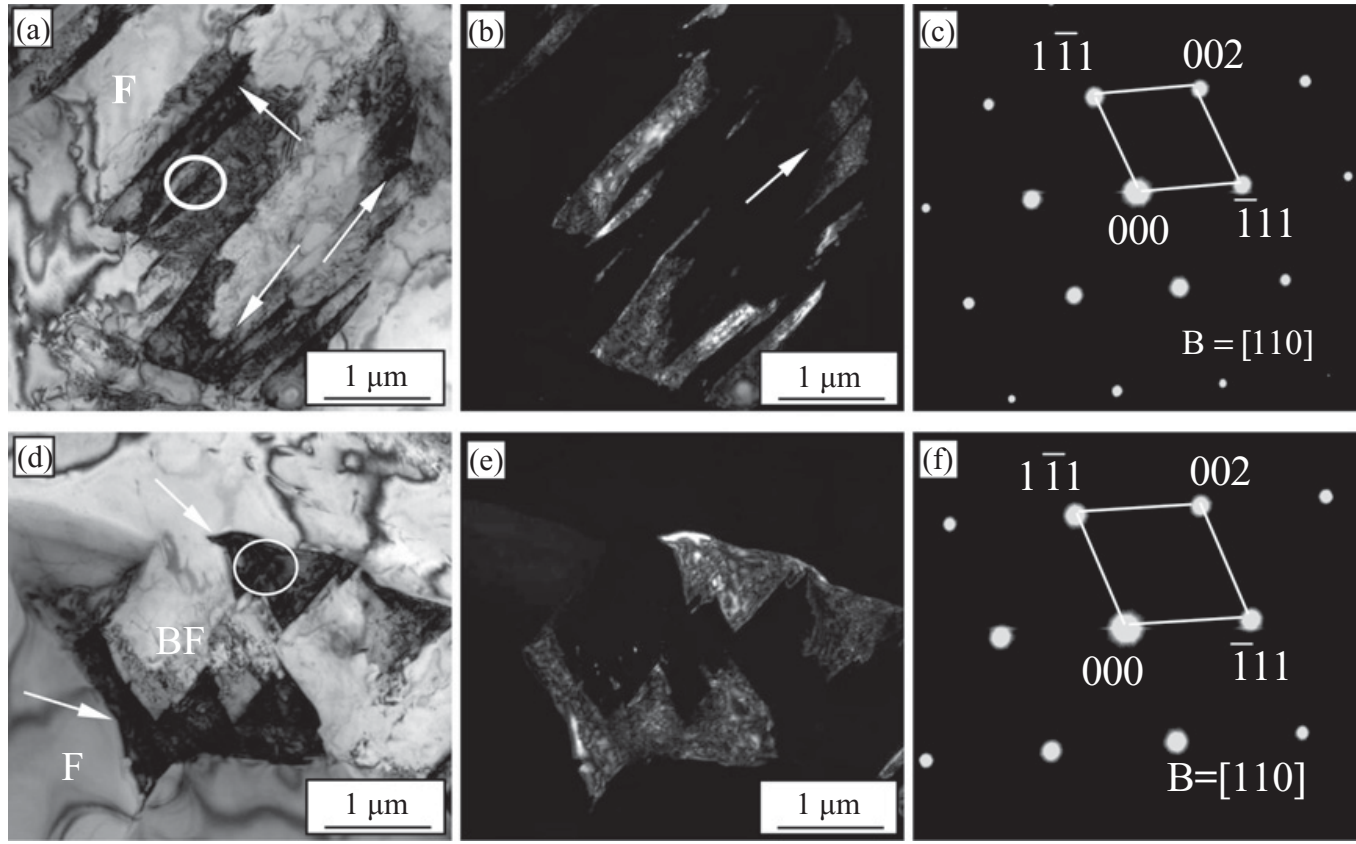

Figure 4. TEM images of film-like and blocky retained austenite in experimental steel: (a) bright field image, (b) dark field image, and (c) diffraction pattern for film-like retained austenite; (d) bright field image, (e) dark field image, and (f) diffraction pattern for blocky retained austenite.

Table 2. Volume fractions of ferrite, bainite and retained austenite of the steel annealed at different temperatures.

\begin{tabular}{|l|c|c|c|}
\hline $\begin{array}{l}\text { Annealing } \\
\text { temperature } /{ }^{\circ} \mathrm{C}\end{array}$ & $\mathrm{F} / \%$ & $\mathrm{~B} / \%$ & $\mathrm{RA} / \%$ \\
\hline 920 & 75.8 & 21.9 & 2.3 \\
\hline 960 & 68.4 & 23 & 8.6 \\
\hline 1000 & 65.6 & 19.3 & 15.1 \\
\hline
\end{tabular}

higher annealing temperature. The similar result was also reported in Ref. [9] that much blocky austenite tended to form when annealed at a lower temperature.

Table 2 lists the volume fractions of ferrite, bainite and retained austenite of experimental steel annealed at different temperatures. Obviously, the volume fraction of ferrite decreases with increasing the annealing temperature. However, with increasing the annealing temperature the volume fraction of retained austenite increases. 


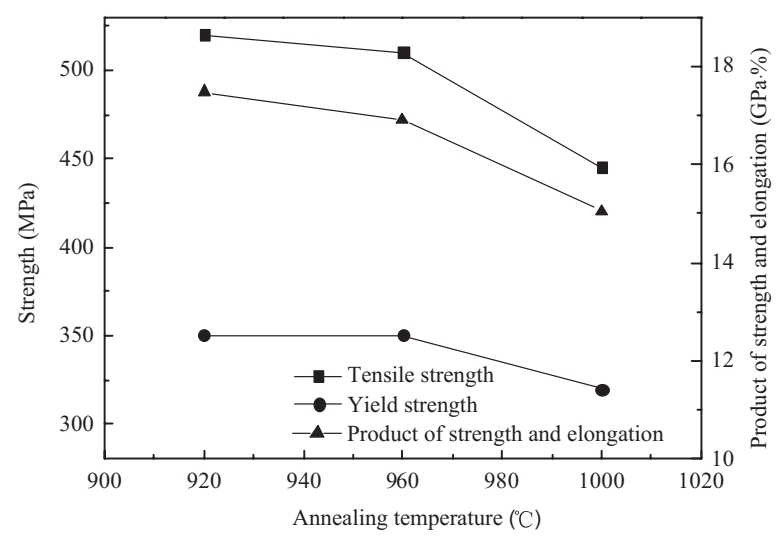

Figure 5. Mechanical properties of experimental steel annealed at different temperatures.

Table 3. Mechanical properties of experimental steel annealed at different temperatures.

\begin{tabular}{|c|c|c|c|c|}
\hline $\begin{array}{c}\text { Annealing } \\
\text { temperature } /{ }^{\circ} \mathrm{C}\end{array}$ & $\begin{array}{c}\text { Tensile } \\
\text { strength/MPa }\end{array}$ & $\begin{array}{c}\text { Yield strength } \\
/ \mathrm{MPa}\end{array}$ & Elongation/\% & $\begin{array}{c}\text { Product of strength and } \\
\text { elongation }(\mathrm{GPa} \cdot \%)\end{array}$ \\
\hline 920 & 520 & 350 & 33.61 & 17.477 \\
\hline 960 & 510 & 350 & 33.17 & 16.917 \\
\hline 1000 & 445 & 320 & 33.83 & 15.054 \\
\hline
\end{tabular}

\subsection{Mechanical behavior}

The mechanical properties of the experimental steel annealed at different temperatures are shown in Fig. 5 and Table 3. From Fig. 5, it can seen that when annealing temperature is above $A_{c 3}$, the tensile strength, yield strength, product of strength and elongation decrease with increasing annealing temperature. When annealing temperature is $920^{\circ} \mathrm{C}$ and austempering is carried out at $450{ }^{\circ} \mathrm{C}$, the experimental steel has the best mechanical properties. In this case, the tensile strength is $520 \mathrm{MPa}$ and the product of strength and elongation is $17.477 \mathrm{GPa} . \%$. Considering that the volume fraction of retained austenite increases with increasing annealing temperature, it can be concluded that the mechanical property of TRIP steels is not only related to the volume fraction of retained austenite, but related to the volume fractions of bainite and ferrite as well. As stated in Ref. [10] by Bhadeshia that the good mechanical properties of TRIP steels are closely related to the hard phase (bainite) and soft phase (ferrite).

As shown in Fig. 6, the retained austenite distribution in experimental steel is characterized by EBSD technology. The blue and red colours denote the ferrite (bcc) and austenite (fcc) phases, respectively. The retained austenite has two different microstructure morphologies, blocky and film-like retained austenite, which is consistent with the previous TEM observations. After tensile deformation, all the blocky retained austenite transformed to martensite, and a little film-like retained austenite remain the same. This means that the mechanical stability of blocky retained austenite is not so well, or the blocky retained austenite is easier to transform to martensite in the early stage of deformation resulting in a high tensile strength during the tensile test [12]. Film-like retained austenite grains were not considered to contribute to the TRIP effect in TRIP steels due to their extremely high stability $[13,14]$. The difference in mechanical properties may be also caused by the different mechanical stability of retained austenite in this experimental steel. 


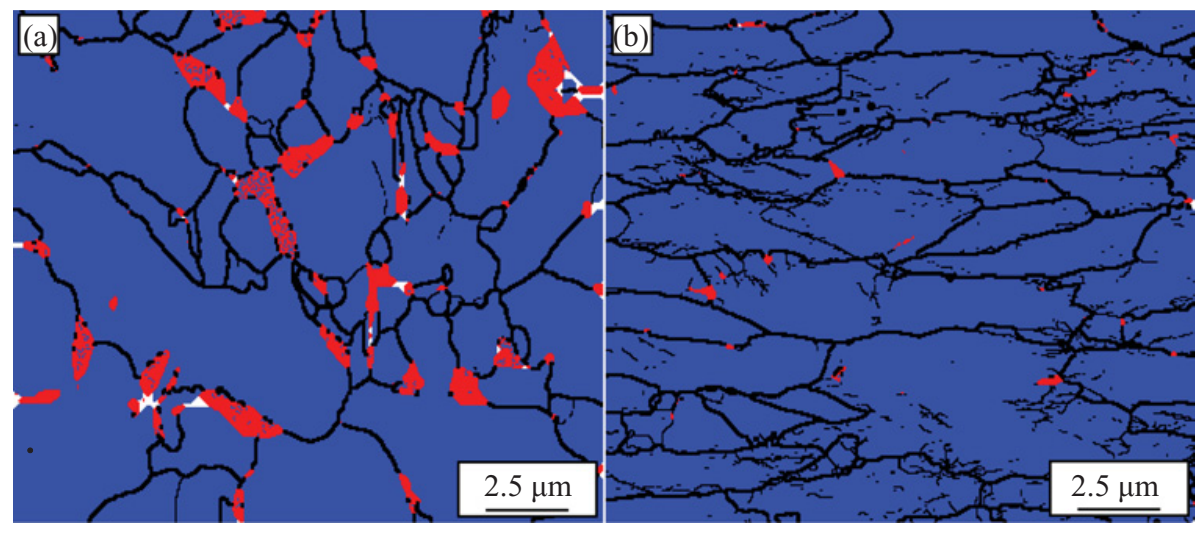

Figure 6. Retained austenite distribution in experimental steel characterized by EBSD technique before (a) and after (b) tensile deformation.

\section{Conclusions}

(1) Due to the existence of $\delta$-ferrite in high Al-low Si TRIP steel, annealing can be conducted above $A_{c 3}$ temperature and the final microstructure consists of ferrite, bainite and retained austenite.

(2) For high Al-low Si TRIP steel, when annealing temperature is above $A_{c 3}$, the tensile strength and the product of strength and elongation decrease with increasing annealing temperature. When annealing temperature is $920^{\circ} \mathrm{C}$ and austempering is conducted at $450{ }^{\circ} \mathrm{C}$, the experimental steel has the best mechanical properties. In such a case, the tensile strength is $520 \mathrm{MPa}$ and the product of strength and elongation is $17.477 \mathrm{GPa} \cdot \%$.

(3) There are two kinds of retained austenite, i.e. blocky and film-like retained austenite in high Allow Si TRIP steel. Blocky retained austenite will fully transform to martensite during tensile deformation, which was beneficial to enhance the strength of steel. Part of film-like retained austenite will remain after deformation, which does not have much contribution to the steel strength.

Financial support from the Fundamental Research Funds for the Central Universities of China (Grant No. N140203001) is greatly appreciated.

\section{References}

[1] C.G. Lee, S.J. Kim, T.H. Lee, S. Lee, Mater. Sci. Eng. A 371, 16 (2004)

[2] E.P. Kwon, S. Fujieda, K. Shinoda, S. Suzuki, Mater. Sci. Eng. A 528, 5007 (2011)

[3] J. Chiang, B. Lawrence, J.D. Boyd, A.K. Pilkey, Mater. Sci. Eng. A 528, 4516 (2011)

[4] H.T. Jiang, W. Ding, D. Tang, J. Iron Steel Research Int. 19,29 (2012)

[5] J. Mahieu, J. Maki, B.C. De Cooman, S. Claessens, Metall. Mater. Trans. A 33, 2573 (2002)

[6] B.C. De Cooman, Curr. Opin. Solid State Mater. Sci. 8, 285 (2004)

[7] S. Chatterjee, M. Murugananth, H.K.D.H. Bhadeshia, Mater. Sci. Technol. 23, 423 (2007)

[8] Y. Zhao, Q.J. Yan, L.Q. Chen, X.Y. Yuan, Acta Metall. Sin. (Eng. Lett.) 27, 389 (2014)

[9] H.L. Yi, P. Chen, H.K.D.H. Bhadeshia, Metall. Mater. Trans. A 45, 3512 (2014)

[10] H.K.D.H. Bhadeshia, ISIJ Int. 42, 1059 (2002)

[11] D. De Knijf, R. Petrov, C. Föjer, L.A.I. Kestnes, Mater. Sci. Eng. A 615, 107 (2014) 


\section{ICNFT 2015}

[12] Z.Z. Zhao, H.X. Yin, A.M. Zhao, Z.Q. Gong, J.G. He, T.T. Tong, H.J. Hu, Mater. Sci. Eng. A 613, 8 (2014)

[13] E. Jimenez-Melero, N.H. van Dijk, L. Zhao, J. Sietsma, S.E. Offerman, J.P. Wright, S. van der Zwaag, Acta. Mater. 55, 6173 (2007)

[14] P.J. Jacques, J. Ladrière, F. Delannay, Metall. Mater. Trans. A 32, 2759 (2001) 